\title{
V.-DISCUSSIONS.
}

\section{PRAGMATISM AND PSEUDO-PRAGMATISA.}

Prof. TAYLor's rejoinder (in N.S., 57) to my ariticism (in N.S., 54 and 55) of some of his recent utterances is so interesting and relevant that it is a real pleasure to reply to it. It has however two sides. The first will doubtless have boen welcomed by all interested in the questions of the hour as throwing a grest desl of light on several of the darkest corners of the pragmatic controversy, and as contributing the most lucid statement of some intellectualist objections the exsct mesning of which has long been a puzzle to all of us, in short as eminently calculated to dispel much of the fog which has hitherto enveloped the real issue. Personally I feel that I now know almost exactly where Prof. Taylor stands, and though he has not come out quite where I expected, I am abundantly grateful to him for clearing up the situation. I can only hope that if I reciprocate in a similar spirit of frankness, he will be able to asy the same for me and that the fog will then be wholly gone.

The other side of Prof. Taylor's article consists of personal grievances and accusations against me, concerning which he seems to me to have said rather more than was either just or necessary. I shall however refer to these as lightly as possible, partly because of my gratitude for the enlightenment aforesaid, partly because I was provoked to give him the annoyance of looking up a good many references (whereof one was I grieve to say misprinted), for which allowance must be made, and, lastly, because it is a waste of time to bandy words with an opponent willing to argue honestly.

Prof. Taylor's main grievance is that he should have been suspected of syncretism, i.e. of attempting to graft on his old stock of absolutism doctrines springing from much younger roots: but I am at a loss to apprehend why he should take this as an insult. I can well conceive, and readily pardon, an absolutist philosopher ransacking all markets in his desire to enrich the barren doctrine that the Absolute is absolnte. And though in this case the rival views look in some lights incongruous enough, I dare not (as yet) affirm it impossible for a philosopher, who fully realised the weakness of the absolutist and the strength of the humanist position in certain respects, to succeed in combining them. There was there- 
fore nothing antecedently preposterous in supposing Prof. Taylor to have made this attempt. Besides both before and since he has given marked proof of a susceptible and syncretist temperament. To take therefore Prof. Taylor's language (of which I gave a representative, though not an exbaustive selection) as aiming at such syncretism was exceedingly natural. It was in fact so taken in seversl quarters, end the mistake, such as it was, was not mine alone nor in the first instance. My own attention indeed was first called to the matter by an approving friend, and it was because of the marked similarity between Prof. Taylor's language and ours that I was moved to serutinise his book so closely. As a result I was puzzled. Many of Prof. Taylor's utterances were distinctly what one may call 'pragmaticoid,' but it seemed on the whole more probable than their pragmatism was not genuine. Still it required very close reading to perceive that he could not mean what he seemed to say. And even when subsequently he came forward as the champion of intellectualism in the McGill University Magazine and the Philosophical Review a doubt remained.

In view of this difficulty and of the fact that Prof. Taylor was still happily alive to be questioned, I thought it best to challenge him by inquiring point-blank what he had meant. The success of this ohallenge is attested by the explicitness of his reply. It entirely removes all doubt as to what, psychologically, Prof. Taylor means. He does not mean to be a pragmatist, and if he has talked pragmatism it has been as M. Jourdain talked prose. But it does not follow that he did not talk it, and that his explanations are as good for others as for himself, and have succeoded in rendering his system logically wherent. The syncretism has not been eliminated but confessed, and it seems to be more deeply rooted in its structure than even now he realises. I am willing indeed to admit that this syncretism is somewhot different in kind from what I supposed. But I am now quite convinced that my critioism was justified both by the admitted laxity of Prof. Taylor's language and the grave tactical error of using 'pragmaticoid' phrases without warning the reader that they did not mean what they might very reasonably be taken to mean.

\section{I.}

I procoed to consider Prof. Taylor's explanations of the incriminsted dootrines in detail. They were, he assures us, derived from

\footnotetext{
1 Most recently ey. in adopting the language, and on many.impoitant questions the views, of Mr. Russell's symbolic logic. And in one desirons of remaining an intellectualist this is doubtless wise. For though this latest of philosophic developments departs from absolutist 'orthodoxy' quite as far as Hamanism, albeit in a diametrically opposite direction, and will, when fully constructed, probably be found to be just as incompatible with it, it appears to be intellectualist to the core, and at least swoids the confusion of logical with psychological considerations which vitiates the traditional 'logic'.
} 
a variety of souras, and that they converged in the same direotion was a coincidence; the case against them was based on 'misapprehensions' or 'commonplaces of philosophic thought'.

(1) Among the latter he reckons his constent use of purpose and teleology, seeing that the 'categories' of end and purpose go back to Plato, Aristotle and Leibniz, all of whom he regards as absolutists. ${ }^{1}$

Now I am quite willing to believe that historically these categories entered Prof. Taylor's mind from the study of Plato and Aristotle, and that he is indebted for their application to Profs. Ward and Royce. But this explanation hardly seems logically safficient seeing that (1) much prominence has been given to the definition of pragmatism as ' a thorough-going recognition of the influence of the purposiveness of thought on all our cognitive activities'; (2) that this was emphasised just because current absolutism has tried to ignore a feature so inconvenient to itself; and (3) that he had himself been exp:essly challenged to show how an Absolute could have a purpose. Or can it really be that Prof. Taylor.has not yet become aware that there is a difficulty here, a difficulty, that is, in conceiving an Absolute, which is really absolute, i.e. a Whole which is complete, possessed by a purpose of completing itself? ?

I hope therefore it will not be thought churlish of me to say that what was wanted was not an account of whence Prof. Taylor took his ideas on the matter, but a proof of their logical congruity with his absolutism. And no appeal to Messrs. Ward and Royce (and still less to the ancients) avails him here. Indeed it seems

${ }^{1}$ I cannot imagine why Prof. Taylor should attribute to me an insane desire to "put Plato, Aristotle and Leibniz under a ban". I have often expressed the greatest admiration for then all. They were all intellectualists no doubt, in some respects, but not one of then can properly be called an absolutist. Leibniz was (predominantly) a pluralist, Plato and Aristọtle were both dualists, as even Dr. Caird reluctantly admits. Horeover, Aristotle's account of the practical reason ( $\phi \rho \operatorname{cov}^{\prime} \sigma s$ ) is pure praguatisin, while Plato's Idea of Good verbally and in weaning coin. cides with the definition of pragnuatisin quoted above. As regards this particular question, moreover, they both had a perfect right to be teleologists, seeing that neither of them identitied the good witl the All, and that this identification is just the great moral and metaphysical stumbling-block in the way of absolutism. I can only suppose therefore that Prof. Taylor is not referring to the historic doctrines of these thinkers at all, but to some strangely mutilated form thereof which he has seen exhibited in sonne of his "Anglo-Hegelian lecture-rooms".

- Prof. Bosanquet apparently prefers to tling himself upon the other horn of the dilemma. He conceives the Whole as in 'change or progress' and therefore in 'tine' (N.S., 57, p. 10). But the result is merely to attritute to the Absolnte (with Lotze) a causeless and meaningless instability ( $c f$. Humanim, pp. 73-75, 78). The mischief lies far deeper. The recognition of ends and purposes always rests ultimately upon selection of some kind. But the Absolute or Whole stands for a principle not of selection but of all-inclusiveness. It cannot therefore be credited with selective emphasis on any of its 'parts'. 
queer to apply to those eminent writers for a gusrantee of a Bradleian metephysic, seeing that both of them have published searching oriticisms of Appearance and Reality, and that it is quite easy, and even necessary, to . understand and develop the doctrines of both in a pragmatist way.

(2) Prof. Taylor assures us that it is a misspprehension to regard his phrase about 'the instinotive demand of the intellect' as an approximation to our views. It was prompted by an aphorism of Aristotle's and a jest of Mr. Bradley's.' I fully believe it. But here again the question is as to the justification. For what business have 'instincts' and 'demands' in what professes to be a pure rationalism? The addition "of the intellect" no doubt makes a difference. Bat, I should have thought, for the worse. For if 'instincts ' and 'demands' penetrate into the very intellect, does not this go far to prove our contention that the intellect itself is not 'purely' intellectual? And of course nothing I said ever implied that I regarded this single remark as 'oommitting' Prof. Taylor to the whole pragmatic doctrine.

(3) As regards the admission of postalates into science Prof. Taylor's explanation seems to read a little lamely. $\mathrm{He}$ mentions no souroes for his inspiration, but excuses himself for escribing a postalatory structure to science on the ground that no one could help seeing it. I could spplaud the sentiment without reserve, did I not remember how very recent the discovery is, and how long the principles of all the sciences were all supposed to be 'axiomatic' truths. And even now it is incomplete. Prof. Taylor himself retains 'axioms' in metaphysics, although (as I have shown and as he has not attempted to dispute) he gives no clear account of what they are, how they are to be known and how they are to be distinguished from postulates. He meraly appeals to the very deceptive (and entirely psychological) test of 'self-evidence'. He likewise excepts from the general procedure of the soiences the single soience of arithmetic, in which he is confident that no postulates can be found. Thas arithmetio, in spite of its scientific isolation, appears to be "the one pinpoint of the truth" upon which, more heroically though more painfally than St. Simeon Stylites, Prof. Taylor once peroratingly deolared himself willing to take his lifelong stand. ${ }^{2}$

Now he had said all this bofore, ${ }^{3}$ and I had duly noted it. But unfortunately the nature of arithmetical assumptions is too large a subject to be discussed on this occasion. It may however give Plof. Taylor some suspicion of the real complerity of these alleged

\footnotetext{
${ }^{1}$ For presumsbly no one would be willing seriously to describe his oun metaphysic as "the finding of bad reasons for what one believes upon instinct". Before evolving a serious doctrine out of it Prof. Taylor should have reflected that the brilliant epigrams of which it forms one must have been put into the preface of Appearance and Reality becanse they would not have fitted into the text.

'MeGill Univerrity Magazine, p. 68. 'L. c., p. 55.
} 
'axioms' to inform him that in leoturing on this subject I find it necessary to distinguish under eight heads the elements in them which rest on postulation, and under five those which depend on sheer empirical fact! For the most purely rational of sciences that is not a bad showing!

Even apart from such debatable matters I am surprised that Prof. Taylor ahould be content to accept the situstion as he conceives it, to acoept, that is, the postulatory procedure of nearly all the soienoes as sheer fact, deserving of no special comment and possessing no significance for his theory of knowledge. If mine had got itself analogously entangled with an alien prinoiple, I should have felt very uncomfortable, especially if I were also aware that the whole of the evidence to which I had pinned my faith was disputed by my opponents.

(4) Prof. Taylor assures me that he meant nothing piagmatio in speaking of thought as an instrument and of the intellect as an "intermediary between a lower and a higher level of immediate apprehension," and thinks that the context should have made this plain to me. Conterts notoriously are diffioult things to allow for. However, in the first case I am quite willing to acoept the interpretation of his contert which Prof. Taylor now gives. The whole argament, he says, was an "objection to the attempt to study the knowing faculty apart from the actual contents of knowledge".

This is excellent, and even more to my liking than his original statement. For it exactly expresses our objection to the intellectuslist severing of logic from psychology. But it seems inconsistent with Prof. Taylor's attitude on page 84 , where he would admit no connexion between logical consequences and actual inferences.' And it seems to square ill with Prof. Taylor's conception of metaphysics as an 'independent' inquiry into the general nature of reality, which is unaffected by the results of the soiences. ${ }^{y}$ For do not those who thus conoeive it attempt to enunciate general truths "apart from the actual contents of knowledge"? I cannot therefore but adhere to my previous conviction that, even though paychologically Prof. Taylor did not realise the scope of what he said, his remerk remains connected with the instrumentalism of Prof. Dowey, and the humanist doctrine of the teleological nature of concepts, which was enanciated by Prof. James so long ago as 1879.

With regard to the intermediary function of thought on the other hand I appear to have in a manner misunderstood Prof. Taylor. I took him to refer to the fact (which well illustrates the purposiveness of thought and has an important besring on the relation of intellection to perception), that judgment enriobes perception and that mediate processes of ognition are ever returning to the immediste form, to which I had myself referred in

1 Cp. a similar argument in Phil. Rov., xiv, 265-288, and below, p. 380.

Cp. Ele. of Mot., first and last chapters. 
Humanism, page 199, and which I have now discussed further in the Journal of Philosophy, iii., 9. I had, of course, stripped off the mystical language and the reference to the Absolute in order to get at the scientific meaning of Prof. Taylor's remark, but if he considers these essential, I have nothing more to say to it.

I am glad that Prof. Taylor has taken the opportunity of explaining to what extent and in whet sense he regards identity as postulatory, even though that sense seems to be nugatory. For his trestment of this point in his book seemed to be so obsoure that I did not feel at all sure about it, and I therefore only referred to it lightly in passing. I must still maintain however that, but for Prof. Taylor's assurances as to his actual state of mind, no one could do otherwise than regard the passage I quoted (p. 354) as clearly subordinating the fundamental oonception of the intellect called 'identity' to practical purposes. In the 'physioal order' at all events it asserts that identity is not 'found' but 'made' or 'taken,' and it plainly renders the 'purpose' which 'identifies' the condition of the 'identity's' existence.

Elsewhere Prof. Taylor goes further and roundly asserts that "all identity appesrs in the end to be teleological" (Ele. of Met., p. 335); I thought it sefer therefore to credit him with more insight into the real nature of this 'axiom' than he now confesses to. I am sorry that Prof. Taylor declines to recognise its complexity, but possibly the reason is that he has so completely misunderstood my attempt to analyse its structure as actually to attribute to me the view that all 'identity' is a matter of postulation. ${ }^{1}$

What is even more regrettable perhaps is that if he had not disolaimed my interpretation, his philosophy would have boen relieved of awkward questions such as these. How, if we only 'reoognise an identity which already exists,' can postulation be said to come in at all and in any sense? What are (human) 'purposes' doing in face of an unalterable order of absolute fact? How does such fact 'call for recognition'? And why does it need to call? And if it is not true that we run the risk of calling things the same beasuse they look similar, and only call them the same when they look the same, will not our resisoning speedily come to a stop? And has not the logiaal axiom thereby been reduced to a psychological accident? And can an intellectualist logic consistently regard a psychological incapacity to discriminate as a legitimate basis for an 'ariom'?

If Prof. Taylor will try to answer these questions for himself, I should not wonder if he came away with a deeper insight into the function of human cognition in apprehending 'independent' fact and 'absolute' truth than any which intellectualism has as yet vouchsafed us. He may even come to think better of poor ' Edwin's' first attempts to construct the 'identities ' he 'recognised '.

${ }^{1}$ Contrast Personal Idealiom, pp. 95-97. 
(5) We come lastly to Prof. Taylor's double criterion of ultimate truth and the 'three' (really two) passeges in which his empiricist version thereof is enshrined. The first of these Prof. Teylor holds to be irrelevant because "it would be quite possible to maintain that nothing is real but experience, and yet to hold that this conclusion itself must be based on other than empirical grounds, in fact to be at once an experientialist in one's metsphysio and a rationalist in one's logic," and this is 'in fact his position'.

I confess to a gasp. I had not suspected Prof. Taylor of so remarkable an enterprise, especially in a context which seemed to insist only on the priority of immediate paychical experience to thought. And even on reflexion, it strikes one as a singularly infelicitons undertaking. For if the logical grounds of metaphysic are to be rationalistically conoeived as "other than empirical," and yet "nothing is real but experience," must not the basis of the system be sought in the unreal? And even if Prof. Taylor does not mean this, but has lapsed into an ambiguous use of the words 'experience' and 'empirical' and regards his a priori reasonings as really falling within experience, is he not proposing to make a part of reality the criterion of the whole? And has he not bound himself to provide an a priori rational deduction of the possibility of all experience? This is, I believe, what even Hegel is now said to have been unjustly suspected of attempting. Anyhow, whether he makes the attempt or not, his doctrine will exemplify one of the most persistent of the failings of intellectualism, viz. its tendency to exalt the rational at the expense of every other aspect of reality.

The 'second ' passage Prof. Taylor admits looks like empiricism; but he 'had always vaguely supposed himself to have got it from Aristotle,' and I have 'concealed the all-important point that the trial referred to was purely logical and a prior i'. But as before in the case of the postulates, I was concerned with the principle and not with the limitation Prof. Taylor arbitrarily imposed on its use. Once it is admitted as a principle that a claim to truth may be tested by trying how it works when applied, why should its applications be restricted a priori? Besides to my thinking the distinction between 'a priori' and 'a posteriori' is only relative and therefore not here relevant.

As for the third passage Prof. Taylor's defence seems to come to a replica of what be said sub (4). For the reasons already stated, it still seems to me to tell distinotly on the empiricist side.

Considering Prof. Taylor's explanations as \& whole therefore I must repeat that though they are beautifully explicit and psycho. logically quite satisfactory, they are not logically adequate. In other words Prof. Tryjlor must be acquitted of any intention to be pragmatic, and I must apologise for suspecting him of departing so far from the path of ortbodoxy : but I may still hold that he has said things of which the meaning and implications are inconsistent with his absolutism, and we now have it on his own 
authority that some of these utterances really were derived from sources alien to it and more akin to my own views. Perhsps we may agree to call these dicta pseudo-pragmatic and expect to find them extensively modified in the next edition of Prof. Taylor's book.

\section{II.}

The earlier part of Prof. Taylor's article challenges me to give a pragmatio explanation of some choice specimens of 'useless" knowledge, and urges some objections which I shall bave great. plessure in meeting. But before taking up these matters, I must correct some misepprehensions of Prof. Taylor's concerning points. of secondary importance.

First as to his inacouracies in quotation. I only referred to them in passing (N.S., 55, p. 353), and they are worth a mention only because he had thought fit to censure Prof. James for oiting the McGill University Magazine as the McGill Quarterly. ${ }^{1}$ One of these moreover has become so habitual with our critics that I do not wonder that Prof. Taylor has difficulty in discerning its existence. He glibly criticises on page 60 " the doctrine that ' the true is the useful," as if that were identical with the assertion that. 'the true is useful' and I had not found it necessary to draw out the formal implicetions of this latter in Humanism, page 38. Not only that, but a little lower down Prof. Taylor indalges in the very ' simple conversion of an A proposition' which I had deprearted in advance, when he infers that "all useful things are true things ". As I had also pointed out, such conversion would have involved us in a denial of useful fictions. 2

The other looked more invidious. I had said ${ }^{3}$ that the disguise of Mephistopheles as a medirval devil had apparently deceived "all the other characters in Faust, except the Lord," and all Goothe's readers except myself. Prof. Taylor thereupon remarked that I shared, by my own confession, "with the Supreme Being the unique distinction of being the sole person in the universe to have fathomed the inner meaning of Goethe's Faust". That is he attributed to me a claim to share with the Deity what I had really professed to share with Goethe. The difference and the inaccuracy are, I should think, fairly obvious. For 'Der Herr' in Goethe's Faust is the Deity as little as the Absolute in Prof. Taylor's Elements of Metaphysics is the ultimate explanation of the universe. However Prof. Taylor wholly disarms any resentment I might have felt by now explaining that he was making a joke I But that I of all men should thereupon be charged with curtailing any philosopher's liberty to make jokes! I hope on the contrary that Prof. Taylor will make more 'jokes' and better ones. Still it is worth remembering that even in jesting it is better to make the cap fit.

Secondly I must disabuse Prof. Taylor of a notion that a nerely

'Phil. Rev., xiv., $265 . \quad$ 'Humanism, p. 87. ' 'Ibid., p. 168. 
antobiographical remark of mine about my feelings towards Prof. James's aritics had any reference to himself. The time referred to was considerably anterior to the date of any of Prof. Taylor'a pablications.

It is a mistake again to read 'disapproval' into my suggestion that on one ocassion Prof. Taylor may have been 'overzealous' in controversy. If I had intended that, I should justly heve exposed myself to Prof. Taylor's rebukes. But I can assure him that I have no sort of objection to controversy. Far from it. I like it. And I do hope Prof. Taylor will not stop on my account. Truth moreover has nothing to fear from controversy. It introduces a human element into soience, which is always stimulating and often enlightening and efficacious in clearing up confusions and misconoeptions. Indeed I feel sure that if, when the new issueswere first raised, they had been honestly argued with instead of being met first with attempts to burke them and then deprecated in quid-me-alta-silentia-cogis-rumpere tones, we should all underatand both them and each other much better, and be on much pleasanter terms to boot.

No; what I was really remarking on was simply the fact that Prof. Taylor had neglected to back up a very sweeping assertion by illustrations. I feared that he had been carried away in the hest of the argument and asserted more then he could substentiate. But now that he has given me three beautiful examples of what he means by assertions which differ as proved truth and demonstrable contradiction while their practical consequences are indistinguishable, I apologise for my suspicion. It will appear later whether by thus repairing his omission Prof. Taylor has also helped his cause.

Lastly Prof. Taylor misses a very simple point when he rebukes. me for taking him for an extreme intelleotualist. So far from thinking him that, I was disposed to question rather whether both he and his master ought not to be far more intellectualistic in order to be sale in their intellectualism. ${ }^{1}$ Nay, Prof. Taylor's seemed to me so shaky that I even thought it possible that he might be on the verge of giving it up altogether. The point of my criticism therefore was that the place he gave to emotion, etc., was inconsistent with his intellectuslism. And I am asconished that he does not 800 this to be the plsin meaning also of the passage he complains of. It was a comment merely on the (to $\mathrm{me}$ ) incongruous combination of emotional interests and desires to know with an ingistence on a belief in 'pure' thought.

Prof. Taylor's manifest failure to see this difficulty moves me therefore to ask him point blank what he takes 'pure thought ' to mean and to be 'pure' from, if not from emotional and volitional contaminations? Have a 'disinterested' interest and a 'pure" thought dependent on emotion never struck him as paradoxes?

${ }^{1}$ For my view of Mr. Bradley in this respect, cp. N.S., 5Z, p. 525. 
Verbal (?) contradictions of this sort seemed to me to run through all his utterances: on the one hand he was strenuous on behalf of 'pure ' thougbt, on the other he emphasised the importance of the emotions which sustained the intellectual life. This could not, I thought, be pure inadrertence. So I tried to elucidate it on the analogy of Kant's refusal to regard the 'pure respect for the moral law' as psychologically classifiable with the other feelings; but I confess I do not really know what Prof. Taylor can mean.

III.

We now come to what is theoretically the most important part of Prof. Taylor's paper, and also that mort welcome to me as being the very thing I had long asked for, viz. his illustrations of sbsolutely useless knowledge. I must begin by expressing my gratification that I should have persuaded him of what I had to point out in N.S., 54, p. 238, viz. that there is a good deal of the truistic about pragmatism. Its fundamental principle is almost a truism, becsuse in 99 out of 100 cases of recognised truth the test whereby this is established is pragmatic. But not quite, as Prof. Trylor supposes. For in the 100th case, it turns out that the alleged 'truth' is no truth at all. Now I had rashly supposed that the bitterness of the absolutists' opposition to the new theory was due to their perception of the deadliness of the pragmatio test in the 100th case, and that they denied its epplicability to the 99 in order to preclude its application to the 100th. But now Prof. Taylor has made it clear that they have actually never understood its application to the 99 ! This astonishing fact is revealed by his choice of examples.

It comes out best in his second exsmple, which I will therefore take first. It is just the sort of simple and elementary example one might choose to illustrate the working of the pragmatic test of truth! The impossibility of answering truly the question whether the 100th (or 10,000th) decimal in the evaluation of $\pi$ is or is not a 9, splendidly illustrates how impossible it is to predicate truth in abstraction from actual knowing and actual purpose. For the question cannot be answered until the decimal is calculated. Until then no one knows what it is, or rather will turn out to be. And no one will calculate it, until it serves some purpose to do so, and some one therefore interests himself in the calculation. And so until then the truth remains uncertain: there is no 'true" answer, because there is no sctual context in which the question has really been raised. We have merely a number of conflicting possibilities, not even claims to truth, and there is no decision. Yet a decision is possible if an experiment is performed. But this experiment presupposes a desire to know. It will only be made if the point becomes one which it is practically important to decide. Normally no doubt it does not become such, because for the actual purposes of the sciences it makes no differenoe whether we 
suppose the figure to be 9 or something else. I.e. the truth to, say, the 99th decimal, is 'true enough' for our purposes, and the 100 th is a matter of indifference. But let that indifference cease, and the question become important, and the 'truth' will at once become 'useful'. Prof. Taylor's illustration therefore conclusively proves that in an actual context and as an actual question there is no true answer to be got until the truth has become useful. This point is illustrated also by the context Prof. Taylor bas himself suggested. For he has made the question about the 100th decimal important by making the refatation of the whole pragmatist theory of knowledge depend on it. And what nobler use could the 100th decimal have in his eyes? If in consequence of this interest he will set himself to work it out, he will discover this once useless, but now most useful, truth, and- triumphantly refute his own contention!

I pause before passing to the other illustrations, in order to correat a serious mistake as to the nature of the pragmatic test into which Prof. Taylor has fallen. He repestedly (pp. 82, 83) assumes that when two practically equivalent assertions are found, I must say that both are 'meaningless'. But this is not at all what I am bound to do.

It was the earliest and simplest formulation of the pragmatic test to declare that when there is no practioal difference between two assertions, they mean the same. They may both be true, or both be false, but neither of them need be meaningless, and clesrly if the one is not, the other cannot be (except of course in so far as it claimed to be an addition to the knowledge conveyed by the other, in which case it may be called meaningless qua such an addition). All that is meaningless is the differenoe between them, and so the question about them. For this obviously dissppears if the alternatives have coincided and the question is reduced to one between two verbally various forms of the ssmo mesning. It is this, the original 'principle of Peirce,' whioh I have always upbeld and which any one familiar with the principle must have seen to be implied in what I said. Prof. Taylor, however, has confused the mesninglessness of the difference between two assertions with the meaninglessness of the assertions themselves. And so it is no wonder he finds the whole pragmatic theory hard to take in. I am a little ashamed to labour 80 simple a point at. such length, but I fear this error may be more widespread then I had suspeoted.

Bofore going on I must also come to an understanding with Prof. Taylor as to the meaning of the term 'practice'. It is my daty to warn him that he is not entitled to take for granted my assent to his conception thereof. When Mr. Bradley proposed to define it as the alteration of existence, I at once protested 1 and gave some ressons for objecting. Prof. Taylor's present definition, ${ }^{2}$ though very similar, is yet less explicit than Mr. Bradley's

$$
{ }^{1} \text { N.S , 62, p. 534. } \quad 2 \text { Like that in Ele. of Met., p. } 121 .
$$


on a vital point. Does " the origination by individuals of ohanges in the temporal order of events "include salterations in their own thoughts and those of others? If it does, 'prectioe' will spread o'ver the whole of Prof. Taylor's 'theoretio' field: if it does not, all human agency will be exoluded from 'practice'.1 In either cose the definition reduces to absurdity.

I must warn him further that in formulating my theory of knowledge I have always laid the chief emphasis not on its relation to 'practice,' but on its relation to purpose. The 'usefulness ' of truth is a direat corollary, not from the supremacy of 'practice ' over 'theory,' but from the purposiveness of thought. 'That is why I have repestedly and unequivocally contended that there is no such thing as 'theory' independent of 'practice,' because ultimately both are relative to purpose. ${ }^{2}$ Our critics, on the other hand, while desoanting on this antithesis, have been strangely silent about the more fundamental doctrine which transcends it. Prof. Taylor therefore has a great opportunity of showling himself superior to his friends by telling us whether or not he admits the purposiveness of mental life, and if he does, whether or not he thinks that it influences our oognitive activities ${ }^{3}$ And it is the more imperative that intellectualists should speak out on this point, beasuse if it is conoeded, the whole of the pragmatio :theory of knowledge may be shown to follow inevitably.

It follows from this that, when a truth is said to be useful, it may be so for any parpose, however 'theoretio' it may seem in the first instance, though ultimately, when the systematisation of ends is fully carried through, it must be useful slso for the highest .end of life, i.e. for what $I$ should call 'practice'. Hence a proposition concerning the ideal creations of a science like arithmetio is true when (1) it tends to the development of the science, or (2) of another scienoe, or (3) that science as a whole has usefal applications to human life. It is unreasonable to expect every detail to be directly applicable; but when a system of thought loses its application to life it ceases to be a soience, and becomes an intellectual game and is useful only as such."

If this be borne in mind it will scarcely be necessary to concern ourselves very elsborately with the technical analysis and justification of what are called 'transfuite numbers'. In epite of itg formidable appearanoe I have been utterly unable to detect :any relevano in Prof. Taylor's 'illustration,' and cannot conceive

I I may suggest as an alternative that to define the practical as ' whatever tendis to the control of events' will be found fairly adequate to the eanse in which the word has been used by us.

' N.S , 52, p. 583, and N.8., 55, pp. 361-862, which latter pasage Prof. -Taylor ignores in spite of the italics and the direct application to himself.

Cp. N.S., 54, p. 237.

- I have never denied the existence and academic importance of such intellectual games. Nor does Pragmatism deny their usefulness as such. It is only disposed to question whether (like other games) they have not been a little overdone. 
how or of what it is, in his opinion, an illustration. I cannot see, that is, how the 'transfinites' can be used as an illustration of " useless truth,' for the simple reseon that they appes themselves to exemplify the usefulness of number. They are, that is, not numbers at all, properly speaking, but a use of number, proceeding from an application of number to space, and the paradores they involve would seem to be ultimately reducible to the old difficulty of representing the continuous by the disorete. Since Zeno's days this has been reoognised as a thorny problem; but how can it possibly affect the velidity of number? I osnnot therefore understand how the use of 'transfinites' in nambering space intervals cen possibly refute any theory as to the nature of number, and can only infer that Prof. Taylor has either mistaken the nature of the 'transfinites,' or (more probably) that of the issue between us.

If however Prof. Taylor dissents from this conclusion I must beg him to make his point a little more explicit. To make his 'illustration ' good, let him show us (1) that the 'empirical' and the 'rationalist' theories of number are the only two conceivable and that one of them is right (for if they are both wrong, they will not illustrate his contention); (2) that they are strictly incompatible, and (3) that there is an issue between them to which the transfinites are relevant. He should next show us (4) how he conceives the 'transfinites' to arise, and (5) to besr on either theory, and (6) explain what are the 'marked logical advantages ' thereby accruing to one of them. Lastly (7) he should try to show how these 'advantages' constitute one theory of number a 'proved truth ' and the otber a 'demongtrable contradiction'. AB regards this last point his language was indeod far from confident, though it would hardly lead one to infer that many oompetent mathematioians (very reasonably) consider the 'transfinites' as equally compatible with either theory. As regards the other points he was wholly ailent. To have argued them all would no doubt have been a long and arduous task, but an illustration which cannot be rendered intelligible without technioslities which had to be avoided was surely a bad one. And it was at least necessary to show that it was relevent, which, so far, it does not appear to be.

I pass therefore to Prof. Taylor's third illastration, that from metephysics. This I may olaim to have answered by antioipation. If it were true that neither Berkeleisn nor any other idealism made any practical difference to the 'every day realism' on which we act, it would add nothing to our knowledge and be held to collapse into a mesningless subtlety, a distinction without a difference. Needless to say, however, this was not Berkeley's opinion : he asoribed to his theory the utmost moral value as disposing of meterialism. Nor is it mine; Prof. Teylor cen find a discussion of the practical difference a real belief in a real idealism should make in Humanism, pages 197-198. 
The notion therefore that Berkeleianism makes no practical difference is Prof. Taylor's, and is no doubt what has helped him to the conclusion that Berkeleianism is false and open to a 'formal logical disproof'. That this should be so would of course be unfortunste for all the theories that make use of Berkeley's proof of idealism (including apparently Prof. Taylor's own ${ }^{1}$ ); but even so the illustration gets into difficulties. For if the Berkeleianism which coincides with 'empirical realism' is a 'demonstrable contradiction,' are we to understand that the latter is a 'proved truth'? If so, what becomes of Prof. Taylor's own idealigm? If not, what does it profit his point to find that sundry errors have practically indistinguishable consequences? Had he not to show that of two such assertions the one may be proved true and the other erroneous ?

I must conolude therefore that Prof. Taylor has nowhere made out his allegation that of two propositions which are practiaally, i.e. for every purpose, the same, the one may be a useless truth and the other a harmless falsghood. The challenge therefore to our critios (which concluded my last article in N.S., 58, p. 175) to confute Pragmatism and have done with it, by producing an indispntable case of useless knowledge, still stands. Prof. Taylor's 'illustrations,' so far from meeting it, have only exhibited our woeful failure (up to date) to impress on him a olear apprehengion of the pragmatic test of tratb. And yet Prof. Taylor had digtingaished himself by the extent to which ho has written about and studied this very matter! Who after this will dare to affirm that the human mind is unbiased by emotion and offers an unobstructed pasage to the entry of pure truth?

Prof. Taylor proceeds further to catechise me as to what 'having consequences' may mean (p. 84), and asks: "do you mean logical consequenoes, assertions which are implied by the truth in question and ought to be recognised as following from it, whether they happen to have been actually drawn or not? Or do you mean actual effects... or both these different things at onco?"

I have quoted this passage at length becsuse it beautifully exemplifies the false antithesis to whioh itg false abstrations conduot the logio of intelleotualism. 'Logical consequences' cannot be separated from psychological effects in the way supposed; they are alwrys first of all psychological effects, and it is only when they are there that their logioal value can be estimated. No truth therefore has logical consequences in abstracto: they come into being only when some one has psychologically drawn them. By saying that they follow 'logically' we only affirm our belief that all 'reasoneble' human minds would consent to draw them; by anying that they existed 'potentially' before we drew them, we

${ }^{1}$ Cp. Ela of Met., pp. 64-66, where, in spite of his protestations, Prof. Taylor never logically gets off subjective ground. 
only antedate conclusions which seem to us so inevitable that we feel we should have drawn them at any time had we hed occasion to do so. For all that, we may often observe that reasonings which possess for one mind the highest degree of logiosl cogenoy are voted individual fads by the rest.' This plainly shows that the feeling of logical necessity is as psyohologiosl as any other.

In short, by calling consequences 'logicel,' we do not reslly mean that they could exist without a psychological contert. We mean that they are psychological oonsequences of a peculiar value which it is important to distinguish. 'Logical' processes are primarily peychological, but seleoted from among the meraly psychological, and honoured with a special mark of distinotion. So far therefore from being acoidental, the peychological consequences are essential to the constitution of 'truth,' and logical consequences would be no consequences at all unless they happened to have been actually drawn'. The science of logio so far from being 'independent of,' i.e. unconneated with, psychology, differs from it only in the difference of purpose with which it works over the same material.?

Prof. Taylor proceeds to find a diffioulty in the obvious fact that 'not only truths but also falsehoods have consequences' which should be easily dispelled by this conception of the logical as a valuable sort of psychological product. He complains that I afford no guidance on the "all-important point" of "how the consequences of truths as such differ from those of error as such": And then he proceeds to quote a passage which plainly gives my answer, to the effect that the 'true' is what forwards and the 'false' what thwarts a human purpose (primarily logical). Or in other words 'true' and 'false' are the forms of logical valne, positive and negative." The answer to Prof. Taylor's question is simply: 'In value'. I cannot put the matter more olearly or concisely.

Of course, this enswer is general, as befits a general theory of knowledge. What answers in detail are 'good' and 'true' as responses to what human interest is a question for the special methodology of each science, and also for social conventions. And until an actual case is presented, it is impossible to show how precisely certein traths forward certain interests.4

'In one of his empirical moods Prof. Taylor has himself made some excellent comments on this fact. See his Problem of Conduct, pp. 369-371.

'Contrast Prof. Taylor's treatment in Phil. Rev., riv., 3, in 'purging logic of psychological accretions' and asserting that "the notion of an individual thinking mind is absolutely irrelevant " to the nature of truth. How all this is compatible with the very "specific emotion" which he finally finds to be essential to the existence of logical assertion (pp. 287288 ) is of course the puzzle noted above (pp. 888-4).

Cp. Humanimm, pp. 54-68 and MrND, N.S., 58 , pp. 160-176.

- Prof. Taylor's poser about the doctor who risks his practice by brutal veracity fails from ignoring the divergences (explained in Humanim, pp. $68-60$ ) which arise from the fact that an individual's purpose is not always 26 
As for the phrase "pro tanto true" whioh Prof. Taylor saspeote of dishonest 'hedging,' it was simply intended to convey a warning that our first predications of 'truth' are rarely our last, as our proximate are rarely our final ends. 'True' like 'good' is predicated at different levels, and as we proceed from the lower to the higher purposes, a valuation made at a lower level is inot of nocessity sustained. It is this process which gives rise to the methodologioal prinaiples, which abound in all the sciences, and mey be called 'truths' or 'fictions' socording to the standpoint, from which they are regarded.

This exhausts the points in Prof. Taylor's artiole which I an think relevant to the issue, though some have had to be treated more briefly than their importence demands. But I hope I may have succoeded in making it olear that if pragmatist epiatemology is more revolutionary, it is also more systematio and adequate, than ita humble beginnings in Dr. Peiroe's magazine article appeared to portend. And it resembles natural products, and differs from the artificial 'systems' of individual philosophers, also in this that it possesses the capacity of growth.

F. C. B. BCHWLER.

socielly valuable nor are his interests always harmonious with those of socisty. The 'good ' and the 'true' $d \pi \lambda \hat{\omega}$ s are not al ways so riml, as Prof. -Taylor might have remembered from Aristotle. Usually the social valuation prevail over the individual, and we are conventionally obliged to coll 'good' and 'true' what may be 'bad' and 'false' for us. Far more complicated cases, which it is interesting to work out, arise how. ever in connexion with the 'transvaluation' of old values and the eatab. lishment of new ones. 